\title{
The DNA field experiment: a randomized trial of the cost-effectiveness of using DNA to solve property crimes
}

\author{
John K. Roman • Shannon E. Reid • \\ Aaron J. Chalfin • Carly R. Knight
}

Published online: 12 September 2009

(C) The Author(s) 2009. This article is published with open access at Springerlink.com

\begin{abstract}
We report the results of a prospective, randomized study of the impact and cost-effectiveness of DNA evidence in investigating property crimes, mainly residential burglary. Biological evidence was collected at up to 500 crime scenes in five U.S. cities between 2005 and 2007, and cases were randomly assigned to the treatment and control groups in equal numbers. DNA processing was added to traditional investigation in the treatment group. A suspect was identified in $31 \%$ of treatment cases and $13 \%$ of control cases. A suspect was arrested in $22 \%$ of treatment cases and $10 \%$ of control cases. Across the five sites, each additional arrest - an arrest that would not have occurred without DNA processing - cost slightly more than US $\$ 14,000$. In the most cost-effective sites, an additional arrest cost less than US\$4,000. Expanding the use of DNA as an investigative tool has profound implications. Since DNA-led investigations are more costly than business-as-usual, substantial investments will be required to expand the capacity of crime laboratories, police, and prosecutors to use this investigative tool efficiently. In time, such a change may also impact the types of crimes of cases processed in the criminal justice system.
\end{abstract}

J. K. Roman $(\bowtie)$

The Urban Institute, 2100 M Street, NW, Washington D.C. 20037, USA

e-mail: jroman@urban.org

S. E. Reid

University of California, Irvine, Irvine, CA, USA

\section{A. J. Chalfin}

Goldman School of Public Policy, University of California, Berkeley, CA, USA

C. R. Knight

Harvard University, Cambridge, MA, USA 
Keywords DNA · Randomized experiment · Cost-effectiveness · Burglary ·

Program evaluation · Property crime

The use of deoxyribonucleic acid (DNA) to identify, confirm, or exonerate suspects has become a staple of many law enforcement investigations. However, due to limited resources available to collect and process biological material, DNA is routinely used only to investigate the most serious violent crimes. Available empirical data, while limited, suggests that DNA has been effective in improving clearance rates for these types of crimes, particularly for sex offenses whose perpetrators most often leave biological evidence behind (Weedn and Hicks 1998). The effectiveness of DNA in those cases has led to efforts to begin expanding DNA evidence collection and processing to other types of crime, such as burglary (FBI 2005).

Funded by the National Institute of Justice, the DNA Field Experiment was designed to provide funds to five communities (Orange County, California; Los Angeles, California; Topeka, Kansas; Denver, Colorado; and Phoenix, Arizona) to expand their DNA collection and analysis to include the investigation of burglaries. Using a prospective, randomized trial, this study tests whether collecting and analyzing biological evidence in property crimes led to better case outcomes. The costs of obtaining improved case outcomes are described, and the cost per outcome is also reported. The results suggest that DNA is an effective investigative tool in property crime cases and that the additional cost can be relatively modest.

\section{Identifying offenders through DNA databases}

The use of DNA analysis in the investigation of sexual assault cases and homicides became more common in the late 1980s and early 1990s, as the use of DNA gained acceptance in legal and scientific arenas. To support the use of this technology, localities, states, and the federal government began creating DNA databases to store, search, and share DNA profiles from convicted offenders, missing persons, and crime scenes. By the early 1990s, most states had begun creating DNA databases, and many had begun collecting DNA from convicted murderers and sex offenders (NIJ 2002). Successful use of DNA in solving crimes led to the creation of the Combined DNA Index System (CODIS), computer software for operating a centralized, national DNA database. This system began as a Federal Bureau of Investigation (FBI) pilot project in 14 states and local laboratories in 1990 and led to the DNA Identification Act of 1994 that created a national DNA database index coordinated by the FBI (FBI 2000).

CODIS is the software that links all DNA index systems (federal, state, and local) which search profiles from crime scenes against DNA profiles from known persons and forensic samples. There are three hierarchical components of CODIS: a locallevel DNA Index System (LDIS), a state-level DNA Index System (SDIS), and a national-level DNA Index System (NDIS). NDIS is managed by the FBI under the authority of the DNA Identification Act of 1994, while management of SDIS and LDIS varies by state. Each level has its own protocols and eligibility criteria for 
submission of DNA profiles. Generally, the criteria are stricter when moving from the local (i.e., LDIS) to the national (i.e., NDIS) DNA index systems. LDIS and SDIS protocols and eligibility criteria vary by jurisdiction, but all states must conform to the submission requirements of NDIS.

The first tier of the system (LDIS) is housed in the forensic DNA laboratory typically operated by local police and sheriff departments. The second tier (SDIS) is housed in a state laboratory that conducts forensic DNA analysis, collects data from local laboratories, performs searches across these sources, and uploads eligible profiles to the national database. There is only one designated SDIS laboratory per state. Finally, the national tier or NDIS collects DNA profiles from participating states and helps support communication and sharing of DNA information between states (NIJ 2002). A weekly search is conducted of all profiles in NDIS. Any matches are reported back to the original submitting laboratory.

Once a hit occurs and the suspect identification has been confirmed, the state crime laboratory sends identifying information to the local crime laboratory (where applicable), which, in turn, forwards that information to the relevant police agency. In three of the four states in our study (California, Colorado, and Arizona) a confirmed CODIS match is sufficient grounds for an arrest warrant to be issued. In these three states, the investigator must collect another DNA sample (usually a buccal swab) once the suspect is in custody. This swab is then analyzed by the local crime laboratory and compared to the original crime scene DNA profile. Generally, this confirmation sample must be analyzed and a match confirmed before the preliminary hearing. This additional confirmation step is generally undertaken to allow analysts at the local crime laboratory to deliver all forensic testimony (should it be required) and serves to confirm the original hit. In Kansas, a confirmed CODIS match is sufficient only for a search warrant to collect and test a new sample from the suspect.

Collection and analysis of DNA from property crime scenes remains fairly atypical. Generally, the process of investigating a burglary is as follows. Upon receipt of a call for service, a patrol officer is dispatched to the crime scene. If the officer finds no suspect at the scene, the victim is interviewed and a list of stolen items is collected. The responding officer may collect fingerprint evidence or canvass for witnesses. Residential burglaries with no suspect present are typically low priority calls in most law enforcement agencies. Officers are under pressure to clear scenes quickly, and thus thorough searches of burglary scenes for physical evidence are atypical (exceptions are made in high-dollar burglaries, cases with a celebrity victim, and cases thought to be part of a long series). The case is then turned over to an investigator for further processing. The investigator will review physical evidence and leads from witnesses, and may re-interview the victim. If no suspect leads result from these activities, the investigation will effectively end there (usually within two weeks of the crime) pending new investigative leads from fingerprints, new witnesses, or recovery of stolen items. Processing of physical evidence for DNA is typically not performed. Since most burglaries yield few leads, burglary has the lowest clearance rate of any UCR Part I crime, about $12.5 \%$ (FBI 2007).

The limited use of DNA to aid burglary investigations may be due in part to uncertainty about its effectiveness and also to the expectation that expanded use of 
DNA will add substantial costs to investigations. Few empirical studies have directly studied the efficacy of DNA evidence in solving property crimes. Three pilot projects to reduce DNA backlog in Miami-Dade (Florida), New York City, and Palm Beach County (Florida) provide some indirect evidence of the potential of the approach (Zedlewski and Murphy 2006). In New York City, the pilot study found that biological evidence collected from 201 burglary scenes yielded 86 CODIS uploadable profiles $(42.8 \%)$ and 31 CODIS matches $(15.4 \%)$, an identification rate that was slightly higher than the national clearance rate for burglaries $(12.5 \%)$ from all investigative sources (FBI 2007). In addition to identifying suspects, 37 forensic matches (18.4\%) linked profiles to other unsolved crimes, including sexual assault and robbery. A similar pilot study of 755 profiles collected at burglary scenes in Miami-Dade and Palm Beach counties yielded 362 (47.9\%) CODIS-acceptable profiles. As more offenders are included in CODIS, identification of suspects using DNA will likely increase.

While the use of DNA to solve property crimes in the United States is a relatively new idea, there is some international experience with this approach. The United Kingdom Home Office began their DNA Expansion Programme in 2000. The project provided funding to police in England and Wales to collect DNA samples from all known offenders and to fund increased collection of DNA material at crime scenes, particularly for volume crimes (burglary and vehicle crimes) that had low closure rates (Home Office 2004, 2005). The DNA Expansion Programme resulted in a 74\% increase in DNA material collected, a 76\% increase in DNA submitted for processing and a $32 \%$ increase in crime scene samples uploaded into the National Database (2000-2005). The Programme increased the number of crime scenes where DNA material was collected from $7.3 \%$ in $2000 / 2001$ to $12 \%$ in $2004 / 2005$ (by 2008 crime scene investigators were visiting $90 \%$ of domestic burglaries). High volume crimes accounted for $61 \%$ of crime scenes in which DNA was found. Where DNA evidence was collected, $45 \%$ of crime scenes yielded a DNA profile that was uploaded into the National Database.

As a result, while the overall detection rate in burglaries was $16 \%$, suspects were identified in $41 \%$ of cases where biological evidence was collected (Home Office 2004, 2005). The Programme also estimates that approximately 50\% of the DNA database-derived detection led to a conviction and $25 \%$ of the convictions led to custodial sentences (Asplen 2004). In the Pathfinder project, the Home Office's Forensic Science Service estimated that while fingerprints are found in six times as many crime scenes as DNA, DNA generates a higher proportion of matches per crime scene (Burrows et al. 2005). The Pathfinder Project also found that police officers placed the highest value on DNA identification, ahead of fingerprints, when ranking the most important forensic evidence to identify a suspect (Burrows et al. 2005).

The paper is organized as follows. The first section describes the demonstration. This is followed by a discussion of the research method used in the impact analysis, the cost analysis, and the cost-effectiveness analysis. The results are then presented in the same order: impact, cost, and cost-effectiveness. The attributes of suspects that are identified by DNA in high-volume cases are also discussed. The paper concludes with a review of the study's findings and a discussion of the implications for the criminal justice system if DNA is routinely collected in high-volume crimes. 


\section{Research design}

Each of the five demonstration sites received funding beginning in financial year (FY) 2005 and the experiment began enrolling cases in September 2005. The first samples were collected in Orange County in December 2005 and all sites completed case enrollment by July 2007. Final case outcomes were observed as of October 31, 2007. All five sites collected samples from commercial and residential burglary scenes. In Phoenix and Topeka, samples were collected from theft from auto crime scenes as well. Once biological evidence was collected at a crime scene, the research team was notified, and the case was randomly assigned to either the treatment or control group. Random assignment of cases was controlled by the evaluator in all five sites, and police agencies were not informed which cases had DNA evidence tested and which did not. However, evidence collection, investigative protocols, and prosecutorial practices varied across the five sites. A brief description of key differences in practice across sites follows.

The Kansas Bureau of Investigation (KBI) led the demonstration project in Topeka. Police officers were responsible for the collection of biological evidence from crime scenes. This represented a significant change in protocol in Topeka as crime scene investigators (CSIs) had previously been responsible for that task. Topeka patrol officers collected biological evidence from 260 property crime scenes during the project period. There were some disincentives in Topeka that may have dissuaded law enforcement from aggressively pursuing property crime investigations. Topeka employed the least strict sentencing practices, as many felony burglars receive a sentence of probation instead of prison. And, unlike the other four sites, in Topeka, identification of an offender via DNA is not sufficient grounds to issue an arrest warrant. Before an arrest warrant is issued, an investigator must obtain a confirmation sample, either through a voluntary contribution from the suspect, or by court order via a search warrant. Only after a sample is obtained, analyzed, and found to confirm the match is an arrest warrant issued.

In Denver, the police department, crime laboratory, and District Attorney's office maintained a collaborative partnership to direct the demonstration. Crime scene investigators trained in biological evidence collection were primarily responsible for collecting bodily fluids from property crime scenes, while patrol officers and detectives were allowed to collect and transfer an entire evidence item to the laboratory for forensic analysis. Overall, Denver employed the strictest prosecution regime of any site, with possible sentences of up to 60 years for serious habitual burglars. Denver also allowed the filing of 'John Doe' warrants, where the DNA profile rather than a suspects name is identified on an arrest warrant. Use of 'John Doe' warrants allows a prosecutor to stop the clock on the statute of limitations in cases where DNA was collected but no suspect was identified by name.

The City of Phoenix and the Maricopa County Attorney's Office collaborated to direct the DNA Field Experiment. The Phoenix Police Department's Laboratory Services Bureau Forensic Biology Section trained responding officers and detectives in the collection of DNA. Early in the demonstration, the Phoenix site experienced several logistical difficulties. Initially, officers responding to a crime scene had to return to their precinct to access a DNA collection kit, extending the average time out of service for a burglary call. In addition, officers were not allowed to leave a 
scene until an officer trained in evidence collection arrived. At the same time, officers were pressured to clear burglaries quickly. These hurdles were eventually removed. While these policies may have reduced the likelihood that biological evidence was collected in the early part of the demonstration, the integrity of the randomization was not compromised. Phoenix (along with Los Angeles) sent samples to external laboratories for analysis unless the sample would be completely consumed by laboratory processing or the case was under a rush order.

The Orange County demonstration was led by the Orange County Sheriff's Crime Laboratory. In Orange County, the DNA Field Experiment funding was used to expand the DNA laboratory capacity and to test the probative nature of touch samples. In order to test the efficacy of collecting touch evidence (swabs from an item suspected to have been handled by an offender rather than fluid evidence from saliva or blood), Orange County included a higher proportion of commercial burglaries than other jurisdictions. For the experiment, DNA in Orange County was collected at burglary crime scenes by trained forensic specialists. Once a responding deputy had completed an initial walkthrough of the crime scene, the laboratory was called to determine whether there was sufficient evidence for a forensic specialist to be dispatched for evidence collection. Thus, two issues arose in Orange County that were not encountered elsewhere. First, many DNA profiles were not eligible to be uploaded into CODIS, since it was often difficult to demonstrate that the evidence collected was from the perpetrator, a requirement for entry in to the national CODIS database. Second, in several instances of commercial burglary, more than one establishment was broken into at the same time. Crimes in physically proximate properties were entered into the research database as a single incident.

In Los Angeles, California, the Los Angeles Police Department and the Los Angeles County District Attorney's Office collaborated to expand the collection of DNA to include high-volume burglary crimes. The LAPD Criminalistics Laboratory of the Scientific Investigation Division (SID) trained three latent print technicians and one forensic photographer from the Technical Laboratory to collect DNA evidence. These newly trained CSI technicians responded to burglary scenes to collect DNA evidence and booked the samples into evidence. However, given the small number of evidence collectors, enrollment of samples into the study was limited. Late in the project, additional cases with DNA evidence were identified and enrolled into the study from whole items that had been collected by LAPD patrol officers not participating in the study. All samples collected in Los Angeles were submitted to an external laboratory for analysis, and Los Angeles was the only site to outsource all samples.

\section{Methods}

The evaluation used a prospective block random assignment design to test the hypothesis that processing DNA evidence from high-volume crime scenes would result in more suspects identified and arrested. The evaluation also counted costs associated with processing DNA evidence and estimated additional costs per outcome. After biological evidence was collected, cases were randomly assigned to a treatment or control condition. In treatment cases, DNA was processed to identify a 
viable profile that was subsequently compared to known offender and forensic profiles. Control cases did not undergo DNA testing for at least 60 days. Because the cases/samples in the control condition were not subject to DNA analysis, the control cases followed business-as-usual investigative practices to identify suspects in burglaries. ${ }^{1}$ The study estimates the impact of DNA evidence on key case outcomes: (1) whether a suspect is identified, (2) whether a suspect is arrested, and (3) whether the case is subsequently accepted for prosecution. The average cost of each stage of case processing is estimated as is the average cost per case for each of the three outcomes.

\subsection{Impact}

The impact analysis identifies the causal impact of the processing of DNA evidence on the key case outcomes. Cases were assigned to treatment and control conditions at random. Thus, given a sufficiently large sample, potentially confounding covariates are unrelated to treatment assignment and will not impact the magnitude or the sign of the treatment coefficient in a multivariate impact model. As a result, while causal impacts in quasi-experiments are ordinarily identified using multivariate methods, in four of five sites, we are able to use bivariate measures of impact. ${ }^{2}$ In Denver, some differences in case attributes were observed, and multivariate models were used to isolate the effects of DNA case processing.

Within sites, there is no evidence that the randomization process was compromised. In every prospective random assignment study, the main threat to validity is the threat of crossovers where treatment samples are not treated and control samples are treated. In experimental studies, the difference in observed outcomes is unbiased if and only if there are no crossovers. In this study, only one crossover was observed. In addition, there is no evidence that the police knew which cases were assigned to the treatment condition and which were assigned to the control condition. Likewise, except for DNA processing, there is no evidence that cases in one group were processed differently from cases in the other group.

We collected data on outcomes for treated cases up to 24 months after the case entered the study sample. Control cases where DNA evidence was never tested were followed for the same period. However, the sites were allowed to test DNA evidence in the control cases after 60 days had elapsed. ${ }^{3}$ In practice, DNA evidence for most-but not all-control cases was never tested. Interviews with detectives in the demonstration sites suggested that cases without DNA evidence were unofficially closed about 15 days after the crime was committed if no suspect had been identified. That is, detectives reported that it was rare that new evidence

\footnotetext{
${ }^{1}$ Consistent with modeling business-as-usual practices, evidence collection, investigative protocols, and prosecutorial practices varied across the five sites.

${ }^{2}$ In Denver, several variables describing key case characteristics differed between treatment and control conditions, despite the randomization. As such, multivariate impact models that control for each of these variables were specified. The resulting models yield treatment estimates that do not differ significantly from bivariate differences identified via the randomization. Thus, for consistency, we report the results of the bivariate analyses here. Regression parameters are available from the authors by request.

${ }^{3}$ The stipulation that sites could test control evidence was written into the demonstration agreement and thus could not be altered. One finding of this study is that the time to complete DNA analysis in burglaries was much longer than had been anticipated.
} 
in property crimes emerged after 15 days. Thus, any differences in case outcomes after 15 days would be due only to the DNA testing of the treatment cases. Outcomes for control cases in which DNA evidence was eventually tested were censored at the time the evidence was tested (at that point, those cases crossed-over and became de facto test cases).

To test whether this assumption biased results, we compared case outcomes in two ways. First, average treatment case outcomes were observed over the life of a case and were compared to censored control case outcomes; that is, the outcomes for control cases at the time control case DNA evidence was tested (if ever). This approach therefore assumes that the ultimate outcome of control cases would have been the same as the observed case outcome at the time case outcomes were censored. To test how strong this assumption was, each treatment case was linked to the control case that entered our sample on the nearest date. If that linked control case was tested, treatment outcomes were censored at the date the control case DNA was tested (if ever). The two approaches yield virtually identical results suggesting this was a relatively weak assumption. Thus, for simplicity, we report only the results from the first approach. Analyses using the second approach are available from the authors.

A key issue in presenting the results is determining whether results should be presented as pooled data or stratified by site. While each site followed the same protocols for random assignment as discussed above, there was substantial heterogeneity in evidence collection practices. Thus, some sites (such as Orange County) used the demonstration as an opportunity to test whether new practices, such as a focus on items thought to be touched or handled by suspects, was costeffective, other sites focused on evidence (such as blood evidence in Denver) that was expected to produce better results. The evaluation is therefore best understood not as five analogous sites following a common protocol, but rather as a continuum of possible approaches. While this argues for presenting results only on a site by site basis, we are also sympathetic to the need to present a single statistic that summarizes the average effectiveness of adding DNA to a property crime investigation. In order to test whether DNA did have a significant effect on case outcomes independent of site-level effects, a two-way ANOVA was conducted using a 2 X 5 (Site x Treatment) factorial design with unequal samples across sites for each dependent variable. However, given the substantial heterogeneity pre-randomization, we also present the site-specific results.

\subsection{Cost analysis}

The cost analysis estimates the additional cost of processing a case with DNA evidence. Unit costs were estimated by collecting data on the quantity of resources consumed (including capital and labor) in each stage of sample-processing as well as the price of those resources (e.g., fully-loaded wages associated with labor, or cost of goods consumed in case processing). Data on prices were collected from secondary sources, such as pay scales or retail prices of consumable goods.

Data on quantities were collected via semi-structured interviews with key stakeholders-forensic scientists in state and local crime laboratories, police officers and detectives who investigated burglary cases, and prosecutors. Specifically, key 
stakeholders were first asked to identify each discrete step involved in sample processing in that site. Once all the steps in processing had been identified in each site, each stakeholder responsible for that stage of processing was asked to estimate (in minutes) the length of time required to complete the entirety of the process. Respondents were asked to estimate the duration of processing for the time when a sample was manipulated rather than the length of time for machine processing. Estimates were developed for single samples, rather than for batched processing. So, for example, in Stage 2 of case processing (Table 1), the steps include DNA extraction, quantitation, dilution, concentration, sample cleanup, application, 310/ 3130 setup, gene mapper ID, and technical review. Stakeholders were only asked to estimate the length of time associated with each step while cost estimates were made by the researchers. Total costs were then estimated as the product of the price and quantity for each stage through which a particular sample proceeded. Case-level costs were estimated as the sum of all samples in the case (cost estimates are presented in Table 7, see "Results: Cost"). All prices and quantities were gathered in FY 2006, and costs are expressed in 2006 dollars.

In order to estimate a cost of processing for each case in the sample, cost data were collected for each of six stages of case processing. These costs describe the

Table 1 Stages of case processing

Stage Title Description

$1 \quad$ Preliminary testing

3 CODIS entry

Case verification (state laboratory)

5 Investigation

6 Post-arrest
This stage includes labor and nonlabor resources expended during initial examination and processing of the sample. These steps include initial examination of the item(s), preparation of the test sample, and screening for the presence of human blood and a subsequent review (if necessary)

2 Generation of profile This stage includes labor and nonlabor resources expended once a sample has been identified as containing human DNA and prior to recording a genetic profile. These steps include: DNA extraction, quantitation, dilution, concentration, sample cleanup, amplification, 310/3130 setup, gene mapper ID, and, where applicable, the technical review

This stage includes labor and nonlabor resources expended after obtaining a profile and prior to uploading the profile into CODIS. These steps include recording the DNA profile, determining if the profile meets the criteria for CODIS upload, uploading each DNA profile into CODIS, and, where applicable, a technical review

This stage includes labor and nonlabor resources expended by the state crime lab used to ascertain that an offender match in SDIS is verified in the state's own database. This includes the cost of reanalyzing the sample and reporting the match to the local crime lab. Note: This stage of processing occurs only if the CODIS hit matches to an offender in SDIS, the state's DNA database, and does not apply to forensic matches

This stage includes labor and nonlabor resources expended by police departments to locate, arrest, interview, and book a suspect, as well as resources expended on the generation of reports and technical reviews undertaken by forensic staff prior to arrest

This stage includes additional forensic lab resources involved in processing a confirmation sample from the suspect after arrest. Note: This stage of processing is assumed to occur only if the DNA matched to an offender at the state-level 
average expenditure associated with the completion of each stage in a case. Next, the progress of each case was observed in administrative data, and a cost was assigned to each case only for those stages that were completed (so if a profile could not be generated in a case, no costs for subsequent stages such as CODIS match were counted).

Table 1 describes each of the six stages of case processing for which average marginal costs are estimated. In the first stage (Preliminary testing), items containing potential forensic evidence were examined and tested for the presence of human DNA (if necessary). Next, evidence is swabbed and the samples undergo forensic analyses that seek to generate a DNA profile (Stage 2). If a case was sent directly to an external laboratory, all the costs associated with processing that sample were assigned to Stage 1. While the internal laboratories could stop processing at any point when it was determined that no profile could be generated, the external laboratories charge per sample regardless of the outcome. If a profile is generated, the CODIS administrator must review the profile and available evidence and decide whether or not the sample is eligible to be uploaded into CODIS (Stage 3). Once a profile is uploaded into CODIS, the CODIS database is used to search for an offender match within the state's database. If an offender match is found, it must be verified by the state crime laboratory (Stage 4). Upon notification of a DNA match, the detective assigned to the case will attempt to locate the suspect and, if appropriate, effect an arrest (Stage 5). Finally, once the suspect has been arrested and booked, a detective will draw a confirmation sample which is sent to the local laboratory for analysis (Stage 6).

These six stages of processing were developed to reflect discrete stages during which costs accrued. That is, each stage represents a set of underlying processes all of which must be completed before a determination is made that the sample can proceed to the next stage. The first three stages represent intermediate outcomes related to the forensic processing of evidence. The other three stages represent outcomes related to the identification and processing of offenders. Thus, these cost stages can be easily mapped onto the three dependent variables. For instance, the cost per suspect identified would include all costs through Stage 4.

The cost estimates for each stage include only the additional costs of processing an individual case with DNA; the fixed costs of operating a police agency or a crime laboratory and the costs of capital purchases (such as robotics in the crime lab) are not included. Thus, the costs described here reflect the costs to a police department with a mature crime laboratory that expands processing of biological material to high-volume property crimes, such as residential burglary. The costs to a municipality to set up a crime laboratory or to begin collecting DNA for the first time will be substantially higher. Likewise, several other costs that are indirectly related to DNA case processing are not included in this evaluation. For example, because biological material was identified and collected in every case in our sample, the costs of training personnel to identify and collect biological material and the costs of additional time at a crime scene are not included as the costs for cases in both groups are the same. Given the short evaluation period, other important costs are not observed, including costs of incarcerating offenders identified via DNA. 


\subsection{Cost-effectiveness}

Cost-effectiveness analysis (CEA) is an analytic method that compares relative costs to relative outcomes for two or more experimental conditions. In the CEA model, program inputs are labeled as 'costs' and program outcomes are expressed in their original units and not monetized. This allows program cost per outcome to be compared in two ways. Each dollar of cost can be compared with each outcome to estimate the relative effectiveness of a policy change-for example, the change in arrest rates per each $\$ 1,000$ of investment in DNA analysis. Alternatively, outcomes can be held constant-for example, how much more or less would it cost to use DNA analysis for each additional suspect identified and/or arrested.

$$
C E_{k}=\left(C_{T}-C_{C}\right) /\left(O_{T}-O_{C}\right)
$$

In this equation, $\mathrm{CE}_{\mathrm{k}}$ is the cost-effectiveness ratio for outcome $k . \mathrm{C}_{\mathrm{T}}$ is the cost of an average treatment case and $\mathrm{C}_{\mathrm{C}}$ is the cost of an average control case. $\mathrm{O}_{\mathrm{T}}$ is the incidence of a given outcome (e.g., number of arrests) in the treatment group and $\mathrm{O}_{\mathrm{C}}$ is the incidence of that outcome in the control group. The resulting ratio is the amount of money required to achieve an additional unit of outcome $k$. For each site, cost-effectiveness ratios are calculated for three outcome variables: the cost per suspect identified, the cost per arrest, and the cost per case accepted for prosecution.

Usually, the numerator in the cost-effectiveness ratio is the difference in average costs for treated and untreated cases. For this particular analysis, the costs associated with the control group are zero; the cost estimates are average marginal costs, e.g., the additional costs associated with case-processing over and above the costs normally incurred during the course of processing a case using traditional investigative procedures. Thus, the cost-effectiveness can be improved either by reducing $\mathrm{C}_{\mathrm{T}}$ or by increasing the difference in outcomes $\mathrm{O}_{\mathrm{T}}-\mathrm{O}_{\mathrm{C}}$. For each site, outcomes are translated into cost-effectiveness ratios for three outcome variables: the cost per suspect identified, the cost per arrest, and the cost per case accepted for prosecution.

\section{Results}

In this section, we first present cross-site descriptive statistics on the outcomes by case processing and the rates of suspects identified, suspects arrested, and cases accepted for prosecution. Second, we examine the relative effectiveness of DNA compared to fingerprints in identifying suspects and effecting arrests. Next, we present data on the cost of treatment and control cases. Finally, we present costeffectiveness estimates.

\subsection{Descriptive statistics}

As shown in Table 2, there were a total of 1,079 test cases and 1,081 control cases across the five sites. The enrollment target for each site was 250 test cases and 250 treatment cases. This goal was not met in Los Angeles (391 total cases) and Topeka 
Table 2 Total cases collected

\begin{tabular}{llll}
\hline & Total test cases & Total control cases & Total cases \\
\hline Denver & 255 & 255 & 510 \\
Orange County & 249 & 248 & 497 \\
Los Angeles & 193 & 198 & 391 \\
Topeka & 131 & 129 & 260 \\
Phoenix & 251 & 251 & 502 \\
Total & 1,079 & 1,081 & 2,160 \\
\hline
\end{tabular}

(260 total cases) Three of the sites (Denver, Orange County, and Phoenix) met the goal of enrolling at least 500 cases. $^{4}$

In Table 3, we evaluate the contribution of DNA evidence to case outcomes by estimating the proportion of all treatment cases that successfully completed each stage of case processing.

Across all sites, in treatment cases, a profile was generated from biologic material collected at a crime scene in $70.3 \%$ of cases. More than half of treatment cases in the study yielded a profile that was uploaded into CODIS, $23.3 \%$ of cases resulted in a CODIS hit and 19.4\% yielded a suspect identification via that CODIS hit. In 14.4\% of all test cases, an arrest was made on a suspect identified in CODIS. In $13.0 \%$ of all test cases, the prosecutor accepted a case against a defendant who was identified by a CODIS hit. There is substantial variation in these \%ages, as, for instance, a suspect was arrested via a CODIS hit in less than three\% of cases in Orange County and more than one-third of cases in Denver.

However, while these data describe important bottom-line findings on the relative effectiveness of DNA in property crime investigations, they mask the sources of variation. Table 3 also describes the percentages of cases that advanced to the next stage of processing. Overall, $77.5 \%$ of all test cases yielded a profile that was uploaded into CODIS. Of cases where a profile was uploaded into CODIS, $42.5 \%$ of profiles yielded a CODIS hit. A suspect was identified from the CODIS hit $88.4 \%$ of the time. Given that a suspect was identified, an arrest was made in $69.8 \%$ of cases. If an arrest was made, the case was accepted for prosecution in $90.3 \%$ of cases.

There is considerable variation across the sites, reflecting cross-site differences in practice. In Phoenix and Denver almost all DNA profiles are uploaded into CODIS. In Orange County, where a substantial percentage of cases had DNA collected from evidence presumed to have been touched or handled by a suspect and evidence from commercial burglaries, only $41 \%$ of cases were uploaded, reflecting the difficulty in obtaining probative samples from these sources. Orange County also had the lowest CODIS hit rate, and anecdotal evidence suggests this may have been due to a higher

\footnotetext{
${ }^{4}$ In each of these sites more than 500 cases were enrolled in the sample. Cases were dropped for several reasons, including that the case was subsequently determined not to be from an eligible crime, or that cases were clearly linked (such as in the event that connecting apartments in a building or a duplex were burgled simultaneously). As it became clear early in the study that some cases would become ineligible, we assigned slightly more than 500 cases in Phoenix, Orange Count,y and Denver. All cases were included unless they were deemed ineligible.
} 
Table 3 Outcomes of treatment cases by stage of case processing and progression to next stage $\mathrm{e}^{\mathrm{a}}$

\begin{tabular}{|c|c|c|c|c|c|c|c|c|c|c|c|c|}
\hline \multirow[b]{2}{*}{ Generation of profile } & \multicolumn{2}{|c|}{$\begin{array}{l}\text { All sites } \\
(\%)\end{array}$} & \multicolumn{2}{|c|}{$\begin{array}{l}\text { Denver } \\
(\%)\end{array}$} & \multicolumn{2}{|c|}{$\begin{array}{l}\text { Topeka } \\
(\%)\end{array}$} & \multicolumn{2}{|c|}{$\begin{array}{l}\text { Phoenix } \\
(\%)\end{array}$} & \multicolumn{2}{|c|}{$\begin{array}{l}\text { Los Angeles } \\
(\%)\end{array}$} & \multicolumn{2}{|c|}{$\begin{array}{l}\text { Orange } \\
\text { County }(\%)\end{array}$} \\
\hline & 70.3 & - & 86.3 & - & 45.8 & - & 58.2 & - & 89.1 & - & 64.7 & - \\
\hline CODIS Entry & 54.7 & 77.7 & 82.4 & 95.5 & 33.6 & 73.3 & 57.4 & 98.6 & 65.3 & 73.3 & 26.5 & 41 \\
\hline CODIS Hit & 23.3 & 42.5 & 45.9 & 55.7 & 19.8 & 59.1 & 15.9 & 27.8 & 27.5 & 42.1 & 6 & 22.7 \\
\hline $\begin{array}{l}\text { Suspect Identified } \\
\text { (via CODIS hit) }\end{array}$ & 19.4 & 88.4 & 39.2 & 85.5 & 16 & 80.8 & 14.7 & 92.5 & 26.4 & 96.2 & 5.2 & 86.7 \\
\hline $\begin{array}{l}\text { Suspect Arrested } \\
\text { (via CODIS hit) }\end{array}$ & 14.4 & 69.8 & 33.7 & 86 & 3.8 & 23.8 & 6.8 & 45.9 & 20.7 & 78.4 & 2.8 & 53.8 \\
\hline $\begin{array}{l}\text { Case Accepted for } \\
\text { Prosecution } \\
\text { (via CODIS hit) }\end{array}$ & 13.0 & 90.3 & 32.2 & 95.3 & 3.1 & 80 & 6.8 & 100 & 16.1 & 77.5 & 2.4 & 85.7 \\
\hline Sample Size & 1,079 & & 255 & & 131 & & 251 & & 193 & & 249 & \\
\hline
\end{tabular}

${ }^{a}$ In the six main columns - All sites and the five individual sites- the first sub-column reflects the percentage outcomes of treatment cases by stage overall, while the second sub-column reflects the outcome percentages of treatment cases given completion of the previous stage

percentage of juvenile offenders. Topeka had the highest CODIS hit rate, but the lowest rate of identifying suspects from CODIS. This may be explained by the requirement that police collect additional samples from suspects before an arrest warrant could be issued. The largest cross-site variations in these data are in the proportion of identified suspects who are arrested. Denver, which reported the presence of policies that encouraged aggressive follow-up of suspect identification, arrested $86 \%$ of known suspects. By contrast, the rate in Topeka was $23.8 \%$. Across all sites, if an arrest is made, the case was accepted for prosecution in $90 \%$ of cases.

\subsection{Impact}

In order to test whether DNA did have a significant effect on case outcomes independent of site-level effects, a two-way ANOVA was conducted using a 2 X 5 (Site $\mathrm{x}$ Treatment) factorial design with unequal samples across sites for each dependent variable. The factorial analysis of variance allows us to investigate the main effects of both treatment and site on outcomes, as well as explore the interaction between the two, taking into account unequal samples by site. Results indicate significant main effects for treatment across all three dependent variables. The main treatment effect was significant on suspect identified at $F_{1,2,150}=92.4, p<$ 0.0001 , on suspect arrested at $F_{1,2,150}=55.8, p<0.0001$, and on suspect prosecuted at $F_{1,2,150}=55.0, p<0.0001$. A significant effect of site was found on suspect identified $F_{4,2,150}=58.3, p<0.001$, suspect arrested $F_{4,2,150}=66.4, p<0.0001$, and suspect prosecuted $F_{4,2,150}=61.5, p<0.0001$. In addition, significant interaction effects between site and treatment were found for all three dependent variables - tests for simple effects within sites indicated significant treatment effects. The sample means for the three main outcomes are described in Table 3.

The results show both that there was an independent treatment effect of DNA and that the variation in implementation across the sites explains much of the variation. 
In addition, the results show that there was a significant interaction effect between site and the treatment $(p<0.0001)$. Traditionally, when there is a significant interaction, the preferred approach is to test for significant simple effects within each site (O'Rourke et al. 2005). Results indicate significant treatment effects across all three dependent variables within each site $(p<0.0001)$. Thus, while we report the ANOVA results, we choose to highlight the differences in means within site as the best indicator of the efficacy of adding DNA to burglary investigation.

As seen in Table 4, treatment cases had significantly better outcomes based on independent sample $t$ tests $(p<0.001)$. A suspect was identified in $31 \%$ of treatment cases where biological evidence was present and the evidence was analyzed. A suspect was identified in $12.8 \%$ of control cases where biological evidence was collected but not tested - a statistic similar to the FBI's estimate that $12.4 \%$ of burglary cases are cleared (FBI 2007). In the treatment group, there was an arrest in $21.9 \%$ of cases compared to 10 in control cases. Slightly more than $19 \%$ of treatment cases were accepted for prosecution compared to $8.1 \%$ in the control. It should be noted that cases accepted for prosecution include some cases where a John Doe warrant was filed based on a forensic match and thus no arrest was made. Across the five sites, there were 173 arrests in treatment cases, 87 more than in the control cases.

Table 5 displays the investigative method used to identify a suspect. In the treatment cases, a CODIS hit identified a suspect in about half of cases where a suspect was identified (16\% of all treatment cases). In an additional 3\% of cases, biological evidence provided an investigative lead that eventually identified a suspect. In both the treatment and control groups, a suspect was identified in about $12 \%$ of cases using traditional investigative techniques, including fingerprints.

Biological evidence was collected for every case in both the treatment and control groups. Thus, we are able to test whether there are differences in case outcomes between biological evidence and fingerprint evidence, conditional on the collection of biological evidence (Table 6). In cases where biological evidence was collected, fingerprint evidence was collected in only one-third of cases. We find that DNA leads to a suspect identification, arrest and prosecution much more often than fingerprints. In all cases (including those where DNA evidence was collected but fingerprint evidence was not), a suspect was identified by biological evidence in

Table 4 Suspects identified, arrested, and prosecuted in all sites

\begin{tabular}{llr}
\hline & Treatment & Control \\
\hline Suspect identified & $31.0 \% * * *$ & $12.8 \%$ \\
Suspect arrested & $21.9 \% * * *$ & $10.1 \%$ \\
Case accepted for prosecution & $19.3 \% * * *$ & $8.1 \%$ \\
Sample size & 1,079 & 1,081 \\
\hline
\end{tabular}

Data are reported at the case level

Significance testing is based on independent sample t-tests comparing each treatment group to the comparison group. Some sites considered the issuance of a warrant to be a case accepted for prosecution. The use of John Doe warrants, where the suspect's name is not known is also included in this total

$* p<0.05, * * p<0.01, * * * p<0.001$ 
Table 5 Method used to identify a suspect

\begin{tabular}{llr}
\hline & Treatment & Control \\
\hline Suspect identified & $31.0 \% * * *$ & $12.8 \%$ \\
Traditional Investigation & $11.6 \%$ & $12.8 \%$ \\
CODIS Hit & $19.4 \%$ & 1,081 \\
Offender Hit & $16.4 \%$ & $3.0 \%$ \\
Forensic Hit/Investigative Lead & 1,079 & \\
Sample Size & & \\
\hline
\end{tabular}

Data are reported at the case level

Significance testing is based on independent sample $t$ tests comparing each treatment group to the comparison group. CODIS Hits and Forensic Hit/Investigative Lead were observable in the data; the number of suspects identified using traditional investigation is calculated as the remainder

$* p<0.05, * * p<0.01, * * * p<0.001$

$16 \%$ of cases, whereas individuals were identified by fingerprint in only $3 \%$ of cases. An arrest was made in cases where DNA was tested in $9 \%$ of cases, while an arrest was made following a fingerprint identification in $1 \%$ of cases. When only the subset of cases with both fingerprints and biological evidence are considered, suspects were identified by CODIS (16\%) at twice the rate they were identified by AFIS (8\%). Suspects were arrested following a CODIS hit at three times the rate $(9 \%)$ they were arrested following an AFIS hit (3\%).

\subsection{Cost}

The cost of processing and investigating a case with DNA evidence in a particular site is dependent on a number of factors-wages of forensic scientists, police officers and detectives, the relative labor-intensity of case processing (e.g., the degree to which DNA analysis is automated), the cost of supplies, and the number of samples that are analyzed in an average case. Higher wages, a higher ratio of labor to automation, and a larger number of samples analyzed per case are all associated with higher costs per case. There are also differences in costs due to outsourcing. The two sites that outsourced DNA analysis - Los Angeles and Phoenix - incurred the highest costs. In Phoenix, the cost of case processing to the local laboratory was $\$ 1,093$,

Table 6 Effectiveness of biological and fingerprint evidence

\begin{tabular}{lclc}
\hline & $\begin{array}{l}\text { Percentage of cases where } \\
\text { evidence collected }\end{array}$ & $\begin{array}{l}\text { Percentage yielding } \\
\text { identification of suspect }\end{array}$ & $\begin{array}{l}\text { Percentage } \\
\text { yielding an arrest }\end{array}$ \\
\hline Biological evidence & $100 \%$ & $16 \%$ & $9 \%$ \\
$\begin{array}{l}\text { Fingerprint evidence } \\
\text { (all cases) }\end{array}$ & $33 \%$ & $3 \%$ & $1 \%$ \\
$\begin{array}{l}\text { Fingerprint evidence } \\
\text { (cases where } \\
\text { fingerprints collected) }\end{array}$ & $100 \%$ & $8 \%$ & $3 \%$ \\
\hline
\end{tabular}


more than twice the average cost of local laboratory processing in Denver, Orange County and Topeka. In Los Angeles, the cost of case processing is over three times higher the average of Denver, Orange County, and Topeka, and more than twice as high even after removing the most expensive cost element - the cost of expediting analysis of confirmation samples.

Table 7 presents the cost of complete processing. Overall, the cost of processing a case with DNA evidence from the time the evidence is delivered to the local forensic laboratory until the time that a suspect's confirmation sample is tested ranges from $\$ 815$ in Topeka to \$2,481 in Los Angeles. When each site's average cost estimate is weighted by its number of test cases, the average cost of processing a case from beginning to end across all sites is $\$ 1,394$. As shown, there is considerable variation in the cost of each stage by site.

For the sites that do not outsource DNA analysis, the cost of preliminary testing and analysis through the generation of a profile ranged from \$154 in Topeka to \$327 in Denver. In experimental sites that outsource case processing, Phoenix and Los Angeles incurred a cost of $\$ 729$ and $\$ 980$, respectively. The high degree of variation in the cost of the CODIS entry phase is due primarily to the length of the process needed to determine whether a sample is eligible for CODIS upload and whether or not a large number of elimination samples were typically tested at this stage. Overall, the weighted average cost of the CODIS upload phase was \$74. In all, approximately $37 \%$ of the costs of processing a case with DNA evidence are incurred prior to CODIS upload. This ranges from $20 \%$ in Topeka to $55 \%$ in Phoenix.

Verification of the CODIS hit to a convicted offender profile at the state laboratory added on average $\$ 131$ to the cost of case processing. The cost of investigating offender hits demonstrated considerably less variation compared to each stage of laboratory processing. On average, the cost of investigation is $\$ 365$, ranging from $\$ 300$ in Los Angeles to $\$ 412$ in Topeka. Finally, once a suspect is apprehended, the local laboratory must analyze a confirmation sample drawn from the suspect, the cost of which is highly dependent on whether or not analysis is done in-house. In the four sites that analyze confirmation samples in-house, costs range from $\$ 108$ in Topeka to $\$ 280$ in Phoenix. However, in Los Angeles, where confirmation samples are sent to a private vendor for analysis, the cost of analysis is $\$ 400$ per contractual agreement. In addition, due to rules imposed by the court system, for cases in which the suspect is not currently in custody, Los Angeles pays an $\$ 800$ rush fee for processing within five business days, a cost which considerably adds to the total cost of analysis.

\subsection{Cost-effectiveness}

Across all five sites, the cost per suspect identified was approximately $\$ 4,500$, ranging from a low of $\$ 1,466$ in Denver to a high of $\$ 8,147$ in Los Angeles (Table 8).

On average, the added cost per arrest was about $\$ 14,000$ and the cost per case accepted for prosecution was about $\$ 6,200$. The cost per case accepted for prosecution is lower than the cost per arrest for two reasons: first, Orange County had a very high cost per arrest but no cases accepted for prosecution, driving the 


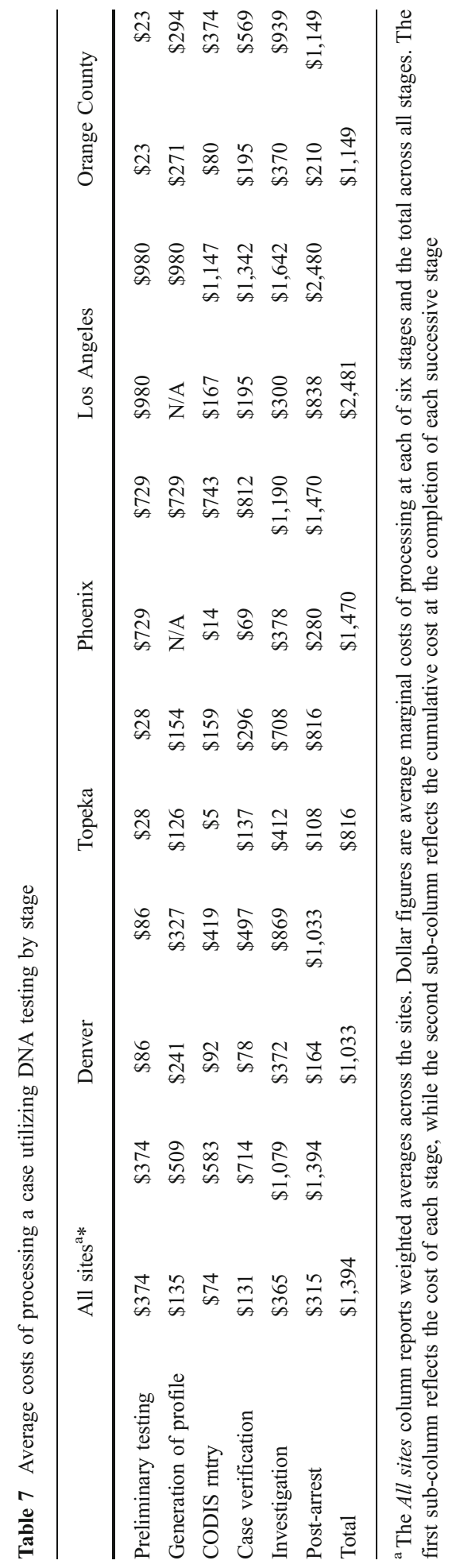


Table 8 Cost-effectiveness of DNA case processing

\begin{tabular}{lccccccc}
\hline & All sites & Denver & Topeka & Phoenix & Los Angeles & Orange County \\
\hline $\begin{array}{l}\text { Expected cost per suspect } \\
\text { identified }\end{array}$ & $\$ 4,502$ & $\$ 1,466$ & $\$ 1,244$ & $\$ 6,170$ & $\$ 8,147$ & $\$ 4,822$ \\
$\begin{array}{l}\text { Expected cost per arrest } \\
\begin{array}{l}\text { Expected cost per case accepted } \\
\text { for prosecution }\end{array}\end{array}$ & $\$ 14,169$ & $\$ 3,679$ & $\$ 5,223$ & $\$ 27,378$ & $\$ 10,319$ & $\$ 19,287$ \\
$\begin{array}{l}\text { Total expected cost per case } \\
\text { through adjudication }\end{array}$ & $\$ 24,840$ & $\$ 1,903$ & $\$ 4,178$ & $\$ 10,785$ & $\$ 12,899$ & $\mathrm{n} / \mathrm{a}$ \\
\hline
\end{tabular}

Expected costs per suspect identified, per arrest, and per case accepted for prosecution reflect the mean cost for that stage, not the cumulative expected cost to reach that stage. Cumulative cost estimates through adjudication are presented in Total expected cost

a The All sites column reports a weighted average across the five sites

${ }^{\mathrm{b}}$ Total excluding cost per case accepted for prosecution; at the conclusion of this experiment, no case in Orange County had come to the end of adjudication

average cost per arrest up without similarly increasing the cost per prosecution. In addition, many cases were accepted for prosecution via a John Doe warrant even though no arrest was made (saving the cost of apprehending the suspect) and some cases were not accepted for prosecution even though an arrest was made.

Again, it should be noted that these costs are not simply the expected cost per suspect identified, arrested and prosecuted. Instead, they are the added costs of identifying, arresting, and prosecuting burglars who otherwise would not have been caught. Costs accrue for each case in the sample. Thus, the mean cost per site includes the costs for cases that both did and did not yield an arrest. As a result, the cost per outcome can be improved either by improving outcomes by, for instance, focusing on best practices rather than experimenting, or by reducing costs of processing evidence.

\subsection{Characteristics of suspects in high volume crimes}

The data also allow us to test the hypothesis that offenders identified via DNA evidence have more serious criminal histories than those identified via traditional investigation (Table 9). Previous research suggests that burglary is a common offense among serious offenders, that burglars commit crime at high rates, and that burglary and motor vehicle theft are often the first serious crime committed by offenders. In a study of a cohort of incoming California prison inmates, Peterson et al. (1980) found that $13 \%$ of incoming inmates reported burglary as their most serious committed offense, 58\% reported having committed a burglary in the previous three years. The sample reported an average of 15.29 burglaries per year. A second study using the RAND inmate survey found that almost $50 \%$ of the sample reported auto theft as their first serious crime and 30\% stated that burglary was their first serious crime (Petersilia et al. 1978). Using arrest histories to examine rates of burglary offending, Blumstein and Cohen (1987) found an average of 5.7 burglaries committed per year and Cohen $(1981,1983)$ found an average of 5.3 burglaries per year by an individual. When self-report data is used, such as the Rand Inmate Surveys, these numbers change dramatically. Using the second inmate survey, 
Table 9 Criminal history of arrested offenders

\begin{tabular}{|c|c|c|c|c|c|c|c|c|}
\hline & $n$ & $\begin{array}{l}\text { Number of } \\
\text { prior felony } \\
\text { convictions }\end{array}$ & $n$ & $\begin{array}{l}\text { Number of } \\
\text { prior felony } \\
\text { arrests }\end{array}$ & $n$ & $\begin{array}{l}\text { Number of prior } \\
\text { misdemeanor } \\
\text { convictions }\end{array}$ & $n$ & $\begin{array}{l}\text { Number of prior } \\
\text { misdemeanor } \\
\text { arrests }\end{array}$ \\
\hline Treatment (all) & 198 & $2.5 * *(3.0)$ & 186 & $4.5^{* *}(4.6)$ & 183 & $2.1 * *(2.6)$ & 180 & $2.6 * *(3.1)$ \\
\hline $\begin{array}{l}\text { Treatment } \\
\text { (CODIS ID) }\end{array}$ & 147 & $2.9 * *(2.4)$ & 138 & $5.6 * *(4.7)$ & 132 & $2.2 * *(3.3)$ & 132 & $3.0 * *(3.2)$ \\
\hline $\begin{array}{l}\text { Control } \\
\text { (No CODIS ID) }\end{array}$ & 50 & $0.9(1.7)$ & 50 & $1.7(2.6)$ & 50 & $1.6(1.9)$ & 49 & $1.0(2.5)$ \\
\hline
\end{tabular}

Source: Analysis of primary data

This table reports data on the criminal history of suspects identified in experimental cases. There may be multiple suspects for any particular case

$t$ tests separately compare differences between each cohort of the test group to the control group

$* p<0.05, * * p<0.01$

Chaiken and Chaiken (1982) found a range of 116-204 burglaries per year committed by incoming prisoners, Visher (1986) found that both prison and jail inmates reported an average of 98.8 burglaries a year and Chaiken and Rolph (1985) found an average of 114.6 burglaries per year. In a study by Blumstein and Cohen (1987) using arrest histories of cohorts of active offenders, the authors found that there was an increase in arrest rate with age for burglary and narcotics.

Overall, we find that suspects identified within the test cohort were significantly more likely to have more prior felony arrests and convictions, and more prior misdemeanor arrests and convictions. For cases where a suspect was identified and criminal justice histories were available, treatment cases averaged 4.5 prior felony arrests and 2.5 felony convictions. In the sub-group of cases where the suspect was identified via CODIS, suspects in the treatment condition averaged 5.6 prior felony arrests and 2.9 prior felony convictions. By contrast, suspects in control cases averaged 0.9 prior felony convictions and 1.7 prior felony arrests. The differences between the treatment group and the control group were also significant across all four measures.

Two caveats should be noted when interpreting these data. First, a criminal history was only available after a suspect had been identified (or in some cases only after a suspect had been arrested). For many cases, given the short period of observation, no arrest records were available at the time data collection was completed. Thus, criminal histories are only available for $43 \%$ of suspects identified (and 64\% of arrestees). Second, most of the offenders in CODIS at the time of this analysis were entered because they had a prior felony conviction. Thus, as states move toward entering all arrestees into CODIS, the relative severity of the criminal histories of suspects identified via CODIS may decline.

\section{Discussion}

In sum, this paper evaluates the expansion of DNA evidence collection and testing to the investigation of property crimes. We report the results of a prospective, 
randomized study of the cost-effectiveness of DNA in investigating high-volume crimes, including residential burglary, commercial burglary, and theft from automobiles. We find that property crime cases where DNA evidence is processed have more than twice as many suspects identified and arrested, and more than twice as many cases accepted for prosecution compared with traditional investigation. Overall, DNA is at least five times as likely to result in a suspect identification compared with fingerprints, and suspects identified by DNA had at least twice as many prior felony arrests and convictions as those identified by traditional investigation.

\subsection{Limitations}

The study is not without limitations. For this study, a cost-effectiveness analysis was preferred to a full cost-benefit analysis. A CEA was chosen over a CBA here because the timeframe of the study did not permit us to follow all cases to their ultimate disposition, and thus important costs and benefits are not observed. The costeffectiveness analysis avoids that problem by directly associating a cost, such as the cost of generating a profile for the related outcome, e.g., how many arrests were made. Ultimately, though, a full cost-benefit analysis would allow additional comparisons to be made. For instance, if DNA-aided investigations are likely to yield more arrests and more prison time, then one key benefit to society would be the reduction in the number of victimizations committed by DNA-identified arrestees while they are incarcerated. And the length of incarceration and the associated cost would have to be estimated as well. Since the costs of using DNA in any one case are relatively small compared to the costs of prison, the cost-benefit comparison would boil down to whether the monetized benefit of preventing more crimes by incarcerating DNA-identified individuals than was spent incarcerating them. While such a study would be very informative, the conclusion would be developed from a comparison of forecasted rather than observed costs and benefits, which increases the possibility of error.

Overall, if the identification, collection, and processing of DNA evidence becomes business-as-usual in criminal investigations for property crimes, the criminal justice system may be deluged with cases as a result. The question that must be answered at that point is whether the social benefit of reducing crimes by incarcerating these offenders is outweighed by the substantial pressure their incarceration places on the criminal justice system. Such an analysis is beyond the scope of this CEA. Practically, it is unlikely that enough new prisons will be built to house these offenders, and therefore it is more reasonable to presume that incarcerating these offenders will crowd out other offenders. If the offenders crowded out by DNA-identified offenders have lower social costs than the DNAidentified offenders, such a scenario would be cost-effective. However, that study is beyond the scope of the current analysis.

A related limitation to cost-effectiveness analysis is that it does not empirically determine whether the costs per outcome make it worthwhile for local jurisdictions to pursue the expanded use of DNA in law enforcement investigations. The overall mean cost per arrest seems to be too large $(\$ 24,840)$ to expect many jurisdictions to adopt this practice. In part, this may be a function of the evaluation design, e.g., that the long lag between the crime and the arrest meant that we were unable to observe 
the arrest in the study period. One way to improve the cost per arrest is simply to have the yield - the number of arrests - increase. The experiment also indicates that if the cases targeted for DNA-aided investigations are limited to the 'best' cases (crime scenes with blood or saliva) then the cost per arrest would be much lower. However, the Denver results suggest that such an approach would yield a much more modest cost per arrest. Thus, it is probably fair to characterize spending $\$ 3,679$ to arrest a burglary suspect who would otherwise never have been caught, and who averages three prior felony convictions, as a small cost.

Since the study randomized assignment of cases once biological material had been collected, this research does not answer the compelling question of "how many burglary cases potentially yield a biological sample?" If the number of scenes yielding biological evidence is small, then DNA profiles are going to be rare. If the number is high, then the pressure on the criminal justice system from processing these cases will be substantial. Thus, it is an important - and unanswered - research question. One way to preserve scarce resources would be to establish screening procedures to maximize the yield from DNA evidence collection. One approach might be to have 911 call centers screen for high probability crimes (the victim might be asked: "Do you see blood? Do you see any items that have been partially eaten or chewed, a container that has been used for drinking, a cigarette butt that you cannot account for? Was your point of entry unlocked?").

Likewise, as noted, the study was unable to estimate the costs of training additional evidence collectors nor the extra time spent on scene by responders because the costs were identical for both the treatment and control groups (since randomization occurred after evidence collection). However, we note across the five sites that additional training was conducted and the costs appear to be equivalent to a day or two of officer time (or other evidence collectors' time), plus the cost of the trainers (a cost that could be reduced using standardized training tools, such as a DVD). In addition, since training appears to be most effective when it is ongoing, jurisdictions would also need to account for those costs.

Finally, there are several findings here that would benefit from more in-depth research. We note that detectives did not know whether the DNA collected in the case was analyzed or not. Thus, differences in outcomes may be in part due to the attributes of the detective in interviewing an identified suspect. Future research should consider how to train detectives and investigators to maximize the use of DNA in suspect interviews. Also, we note that there is no clear explanation why DNA processing is superior to fingerprint identification in identifying suspects. Fingerprint databases are substantially larger than CODIS, so the finding that DNA is more effective is somewhat unexpected. We also note that there is no clear explanation for why DNA was found at so many more crime scenes than fingerprints. The evidence collector in most instances was also trained in collecting fingerprints (in Los Angeles, for example, latent print technicians were used to collect some evidence). Thus, it is not clear why DNA was collected in many more cases than fingerprints.

\subsection{The future of DNA evidence}

The effectiveness of DNA in solving crimes that have not traditionally been investigated using DNA technology may well have profound impacts on criminal 
case processing in the future. Our research suggests that large numbers of offenders who could be identified via DNA today are not identified by traditional investigations. Resource constraints appear to prevent local authorities from using DNA to identify and prosecute offenders in property crimes. Currently, the capacity of police and laboratories to identify and collect DNA is limited as crime laboratories are severely constrained in their ability to process biological evidence in volume. Prosecutors may not be prepared for the impact of large numbers of cases where DNA evidence is the primary source of offender identification. Without substantial attention to the potential impacts of DNA on criminal justice processing - both intended and unintended-police, laboratories, and prosecutors may not fully exploit this new technology.

\subsubsection{Demand for laboratory services}

If the results here are replicated in the field, that there will likely be a substantial expansion of the use of DNA. However, there is no evidence that there is currently sufficient state and local laboratory capacity to process that evidence. Many questions must be answered to determine how quickly crime laboratories can be equipped with the resources to meet the increased demand for DNA processing. In order to increase the number of cases solved by DNA, what is the necessary additional investment in expanding laboratory capacity? What types of capital investments in new technology are required? How many additional evidence collectors are needed and of what type (police, criminalist, other technicians, or DNA collectors)? Should jurisdictions seek to increase their in-house laboratory capacity or rely on outsourcing to private laboratories? Our research demonstrates that outsourcing is more expensive than inhouse processing, but we are not able to account for major fixed capital costs. It is clear that realizing the potential of DNA processing will require substantial increases in resources. The opportunity costs of those resources should be carefully considered before this investment is made.

\subsubsection{Investigation and prosecution}

A concern about focusing resources on the investigation of crimes-including high volume crime such as burglary-is that there will be spillover effects on the investigation and prosecution of other crimes. Does a focus on forensic investigation cause other crimes to be under-investigated due to limited resources? Does the higher closure rate for DNA-led investigations incentivize more investment in those cases and reduced investments in crimes that are investigated using traditional investigative approaches, such as drug crimes, sex crimes where consent is at issue, domestic violence, and robbery? What is the impact on resources available for other forensic investigations (such as traditional detective work, fingerprint collectio, n or other forensics such as footprints)?

In the longer term, there are also a set of important trade-offs that must be considered as the criminal justice system responds to the increase in DNA-led investigations. Does increased reliance on forensic-led investigations incentivize more reactive policing at the expensive of proactive approaches? Will growing reliance on DNA lead to a trade-off away from labor (detectives) in favor of capital 
investments (such as laboratory robotics)? Will resources be made available for warrant squads or other police units to capture identified fugitives (our study suggests that as many as one in three CODIS-identified suspects are not currently being arrested), and where will those resources come from?

\section{Conclusion}

The report's principal finding is that the use of DNA in the investigation of property crimes increases the rate at which suspects are identified, arrested, and prosecuted for property crimes. We find that DNA is more effective than fingerprints in identifying suspects. The combination of that effectiveness and the relatively low marginal cost of using DNA (at least in Denver) suggests that DNA-led investigations may become a more common means of identifying suspects in criminal cases. The implications of that shift would be substantial. DNA analysis is much more expensive than fingerprint analysis, and the resources needed to fund an expansion of capacity would be large. In addition, the use of DNA appears to be very effective in identifying suspects in some kinds of cases - homicide, stranger rape, and property crimes - but less so in other kinds of crimes - domestic violence and drug crimes. If the large investments in capacity to analyze DNA evidence that are necessary to move this investigatory tool into the mainstream are pursued, the mix of crimes that are investigated may also change. In short, if DNA causes a revolution in policing, local jurisdictions would do well to remember that, while DNA is a reliable and effective investigative tool in some crimes, resources must remain available to investigate other criminal matters.

Acknowledgements The authors gratefully acknowledge the National Institute of Justice for funding this research (2005TO090) and in particular wish to thank Ed Zedlewski and Kathy Browning for their guidance and support. This research could not have been completed without the research assistance of Bogdan Tereshchenko, Aaron Sundquist, Kevin Ward, Julie Wilkinson, Lacey Ballantyne, Abby Brown, Erin Balogh, and Alanna Rosenberg. Denise Herz, Scott Decker, and Tim Bynum each made a substantial contribution to both the research and the project by troubleshooting early problems in implementation. Eric Grodsky and Adele Harrell provided critical insights into the evaluation's design and methods. We also wish to thank the anonymous referees for very helpful suggestions. Despite their assistance, all errors are our own. Views expressed here are the authors'. They do not reflect the official position of policies of the Department of Justice, nor the Urban Institute, its trustee or funders.

Open Access This article is distributed under the terms of the Creative Commons Attribution Noncommercial License which permits any noncommercial use, distribution, and reproduction in any medium, provided the original author(s) and source are credited.

\section{References}

Asplen, C.H. (2004). The Application of DNA Technology in England and Wales, final report submitted to NIJ, (NCJ 203971). Available at http://www.ncjrs.gov/pdffiles1/nij/grants/203971.pdf

Blumstein, A., \& Cohen, J. (1987). Estimation of individual crime rates from arrest records. Pittsburg: Working Paper, Carnegie Mellon University.

Burrows, J., R. Tarling, A. Mackie, H. Poole and B. Hodgson. (2005). Forensic Science Pathfinder project: Evaluating increased forensic activity in two English police forces. Retrieved from: http:// www.homeoffice.gov.uk/rds/pdfs05/rdsolr4605.pdf (accessed 20 March 2008). 
Chaiken, M.R. and Chaiken, J.M. (1982). Varieties of Criminal Behavior. Rand Report R-2814-NIJ. Santa Monica, CA: Rand Corporation.

Chaiken, M. R., \& Rolph, J. E. (1985). Identifying high-rate serious offenders. Draft report. Santa Monica, CA: The Rand Corporation.

Cohen, J. (1981). Racial differences in individual arrest patterns. Working paper, presented at annual meeting of American society of criminology. Carnegie Mellon University, Pittsburg: Urban Systems Institute, School of Urban and Public Affairs.

Cohen, J. (1983). Incapacitation as a strategy for crime control: Possibilities and pitfalls. In M. Tonry \& N. Morris (Eds.), Crime and justice: An annual review of research, volume 5. Chicago: University of Chicago Press.

FBI (Federal Bureau of Investigation). (2000) Quality assurance standards for forensic DNA testing laboratories, Forensic Science Communications. Website: http:/www.fbi.gov/hq/lab/fsc/backissu/ july2000/codispre.htm.

FBI (Federal Bureau of Investigation). (2005). National DNA Index System (NDIS): DNA Data Acceptance Standards. Department of Justice: FBI. Washington, D.C

FBI (Federal Bureau of Investigation). (2007). Crime in the United States 2006. Retrieved December 12, 2007 Website: http://www.fbi.gov/ucr/cius2006/offenses/clearances/index.html

Home Office (2004). Reducing burglary initiative online reports. http:/www.homeoffice.gov.uk/rds/ burglary1.html (accessed 27 March 2007). Also available from London: Home Office

Home Office (2005). DNA Expansion Programme 2000-2005: Reporting Achievement. Retrieved from: http://www.homeoffice.gov.uk/documents/DNAExpansion.pdf (accessed 20 March 2008)

NIJ (National Institute of Justice). (2002). NIJ Special Report: Using DNA to Solve Cold Cases. (http:// www.ncjrs.gov/pdffiles1/nij/194197.pdf)

O’Rourke, N. L., Hatcher and E. Stepanski. (2005). Using SAS for Univariate and Multivariate Statistics. Cary: SAS Institute Inc

Petersilia, J., Greenwood, P. W., \& Lavin, M. (1978). Criminal careers of habitual felons. Washington, DC: U.S. Government Printing Office.

Peterson, M., Braiker, H., \& Polich, S. (1980). Doing crime: A survey of California inmates. Santa Monica, CA: The Rand Institute.

Visher, C. (1986) The Rand Inmate Survey: A Reanalysis, in A. Blumstein, J. Cohen, J.A. Roth, \& C.A. Visher, 1986, Criminal Careers and Career Criminals, vol. 2, National Academy Press, Washington D. C., pp. 161-211

Weedn, V.W., and J.W. Hicks. 1998. The Unrealized Potential of DNA Testing. Washington, DC: U.S. Department of Justice, National Institute of Justice.

Zedlewski, E. and M. B. Murphy. (2006). DNA Analysis for 'Minor' Crimes: A Major Benefit for Law Enforcement. National Institute of Justice Journal 253 (January): 2-5

John K. Roman Ph.D. is a Senior Research Associate at the Urban Institute and a Lecturer at the University of Pennsylvania. His research focuses on evaluations of innovative crime control policies and programs. He has studied the demand for community-based interventions with drug-involved arrestees, the impact of DNA on the criminal justice system, the cost of the death penalty, specialized courts and prisoner reentry.

Shannon E. Reid is a Ph.D. student at the University of California, Irvine studying Criminology, Law and Society. She is currently working on several projects involving gang-based behavior in the Los Angeles, CA area. Prior to attending UC Irvine, Ms. Reid worked for the Urban Institute on projects such as the DNA Field Experiment, Project Safe Neighborhoods and as project manager for the National Institute of Justice-funded project, Alcohol Availability, Distribution Policies and their Relationship to Crime and Alcohol-Related Injury. 
Aaron J. Chalfin is a Ph.D. student at the University of California, Berkeley's Goldman School of Public Policy. Prior to that, he was a Research Associate at the Urban Institute's Justice Policy Center where his research focused on evaluations of criminal justice programs and the application of cost-benefit analysis to crime policy.

Carly R. Knight is a Ph.D. student at Harvard University in the Department of Sociology. Prior to that she was a Research Associate at the Urban Institute where her researched focused on fear of crime, marriage, prisoner reentry, the death penalty, public housing and cost-benefit studies of a variety of innovative polices and programs. 